\title{
The association of race with timeliness of care and survival among Veterans Affairs health care system patients with late-stage non-small cell lung cancer
}

\author{
This article was published in the following Dove Press journal: \\ Cancer Management and Research \\ 23 July 2013 \\ Number of times this article has been viewed
}

Leah L Zullig ${ }^{1,2}$

William R Carpenter ${ }^{2}$

Dawn T Provenzale ${ }^{1,3}$

Morris Weinberger ${ }^{1,2}$

Bryce B Reeve ${ }^{2}$

Christina D Williams'

George L Jackson ${ }^{1,4}$

'Center of Excellence for Health Services Research in Primary Care, Durham Veterans Affairs Medical Center, Durham, NC, USA; ${ }^{2}$ Department of Health Policy and Management, University of North Carolina at Chapel Hill, Chapel Hill, NC, USA; ${ }^{3}$ Division of Gastroenterology, Duke University, Durham, NC, USA; ${ }^{4}$ Division of General Internal Medicine, Duke University, Durham, NC, USA
Correspondence: Leah L Zullig Health Services Research and Development (152), Durham Veterans Affairs Medical Center, 508 Fulton Street, Durham, NC, USA 27705

$\mathrm{Tel}+\mathrm{I} 91928604$ I I ext 7586

Fax + I 9194165836

Email zullig@email.unc.edu
Background: Non-small cell lung cancer is the leading cause of cancer-related mortality in the United States. Patients with late-stage disease (stage 3/4) have five-year survival rates of $2 \%-15 \%$. Care quality may be measured as time to receiving recommended care and, ultimately, survival. This study examined the association between race and receipt of timely non-small cell lung cancer care and survival among Veterans Affairs health care system patients.

Methods: Data were from the External Peer Review Program, a nationwide Veterans Affairs quality-monitoring program. We included Caucasian or African American patients with pathologically confirmed late-stage non-small cell lung cancer in 2006 and 2007. We examined three quality measures: time from diagnosis to (1) treatment initiation, (2) palliative care or hospice referral, and (3) death. Unadjusted analyses used log-rank and Wilcoxon tests. Adjusted analyses used Cox proportional hazard models.

Results: After controlling for patient and disease characteristics using Cox regression, there were no racial differences in time to initiation of treatment ( 72 days for African American versus 65 days for Caucasian patients, hazard ratio $1.04, P=0.80$ ) or palliative care or hospice referral (129 days versus 116 days, hazard ratio $1.10, P=0.34$ ). However, the adjusted model found longer survival for African American patients than for Caucasian patients (133 days versus 117 days, hazard ratio $0.31, P<0.01$ ).

Conclusion: For process measures of care quality (eg, time to initiation of treatment and referral to supportive care) the Veterans Affairs health care system provides racially equitable care. The small racial difference in survival time of approximately 2 weeks is not clinically meaningful. Future work should validate this possible trend prospectively, with longer periods of follow-up, in other veteran groups.

Keywords: non-small cell lung carcinoma, Veterans Affairs, quality of health care

\section{Introduction}

Lung cancer is the leading cause of cancer-related death, accounting for $29 \%$ of all cancer-related deaths among men. ${ }^{1}$ Non-small cell lung cancer (NSCLC) is responsible for approximately $85 \%$ of lung cancers. ${ }^{2}$ NSCLC has a dismal prognosis, with 5-year survival rates ranging from $49 \%$ for patients with stage $1 \mathrm{~A}$ of the disease to approximately $1 \%$ for those with stage $4 .^{2}$ Because survival rates are poor, the goal of much therapy for late-stage NSCLC patients is palliative, often focusing on formal referrals to palliative care and/or hospice services. For patients with late-stage disease, recommended treatment ranges from chemotherapy and radiation with or without surgery 
(stage $3 \mathrm{~A}$ ), to chemotherapy and radiation without surgery or chemotherapy alone (stage $3 \mathrm{~B}$ ), to chemotherapy alone for patients with metastatic disease (stage 4). ${ }^{3,4}$

There is a clear link between quality of care and patient outcomes. Receipt of timely, stage-appropriate care for NSCLC patients can increase the length of survival. ${ }^{5}$ Despite the Institute of Medicine prioritizing the receipt of timely treatment as a measure of quality, ${ }^{6}$ many studies have identified differences in care quality among NSCLC patients of diverse races that may contribute to racial differences in outcomes. ${ }^{7}$ In fact, there is evidence of racial disparities in care quality measures throughout the NSCLC treatment trajectory. Proper staging is essential for effective treatment planning, yet there are racial differences in receipt of positron emission tomography imaging to accurately stage patients. ${ }^{8}$ Once a patient has been staged, for those with early-stage NSCLC, timely receipt of surgical resection has a critical impact on survival outcomes. Several studies have shown that African American patients are less likely to receive surgical resection than their Caucasian counterparts. ${ }^{9,10}$ Racial differences also exist in terms of patient treatment refusal rates, ${ }^{11}$ and appropriateness and timeliness of care among Medicare beneficiaries. ${ }^{12,13}$ One study found that relative to Caucasian patients, African American patients were 34\% less likely to receive timely surgery, chemotherapy, or radiation for stage 3 NSCLC, and 51\% less likely to receive chemotherapy in a timely fashion for stage 4 disease. ${ }^{12}$

Although the existence of racial disparities in NSCLC is well documented, the cause of these racial differences is complex. Reasons include a cumulative effect of both patient and health system factors. Evidence suggests that when patients receive the right care at the right time, there is little racial difference in survival rates. For example, among patients in the Surveillance, Epidemiology, and End Results database, there was a $3 \%$ absolute difference in survival favoring Caucasian patients over minorities. ${ }^{14}$ In an analysis of late-stage NSCLC Medicare beneficiaries, the 5-year survival rates for Caucasian and African American patients were $17.7 \%$ and $19.6 \%$, respectively. After controlling for socioeconomic status, this difference disappeared entirely. ${ }^{5}$ Similarly, after controlling for receipt of surgery, differences in survival rates for early-stage NSCLC patients were comparable across racial groups. ${ }^{15}$ Similar survival rates by race were found among veterans with early-stage disease who received surgery. ${ }^{16,17}$

The Veterans Health Administration, the largest integrated US health care system, is reputed as an equal-access provider. ${ }^{18}$ As such, the Veterans Affairs (VA) healthcare system provides an excellent environment in which to study the quality of cancer care among patients with NSCLC. We hypothesized that if patients received equitable and timely care, there would subsequently be similar survival rates by race. Focusing on patients with late-stage NSCLC (stage 3 and 4), we expand upon previous work by examining racial differences in two dimensions of quality of VA NSCLC care: processes of care (time to treatment) and outcomes (survival).

\section{Methods \\ Data source}

The Veterans Health Administration Office of Analytics and Business Intelligence (formerly the Office of Quality and Performance) conducted the External Peer Review Program Lung Cancer Special Study to evaluate the quality of lung cancer care provided in the VA. As described previously, ${ }^{19}$ patients were identified through the VA Central Cancer Registry. ${ }^{20}$ Patients were eligible for the External Peer Review Program study if they had been diagnosed with lung cancer between October 1, 2006, and December 31, 2007; had documented pathological confirmation of lung cancer in the electronic medical record; and had survived at least 31 days after diagnosis. Patients were excluded for any of the following reasons: lung cancer diagnosed during autopsy; enrollment in hospice less than 31 days after diagnosis; enrollment in a cancer clinical trial; preexisting or concurrent diagnosis of metastatic cancer (other than lung cancer); documentation of comfort measures only; or life expectancy of 6 months or less. Data were manually abstracted from a national electronic medical record by trained abstractors between February 3, 2010, and August 11, 2010.

\section{Measures}

The analytic data set consisted of African American and Caucasian patients with pathologically confirmed late-stage (stage 3 or stage 4) NSCLC. We assessed three dependent variables. We included two process measures of care timeliness: (1) time from diagnosis to initiation of treatment (surgery, chemotherapy, radiation therapy, or admission into palliative care or hospice) and (2) time from diagnosis to referral to palliative care or hospice. The third measure was time from diagnosis to death. Death information was obtained during data abstraction, approximately 2 years from diagnosis. For all measures, time was expressed as the number of days between events.

The primary independent variable of interest was patient race. Because there were relatively few non-African American 
minority patients in the cohort $(\mathrm{N}=56)$, we restricted our analyses to African American and Caucasian patients; we lacked data on Hispanic ethnicity. Covariates included demographic characteristics (age at diagnosis, marital status, and geographic region) and clinical factors (stage at diagnosis and performance status) previously associated with timeliness of care. ${ }^{21,22}$ Patients were considered to have poor performance status if the medical record contained documentation of any of the following: Eastern Cooperative Oncology Group score $>2$, Karnofsky Performance Status Scale score $<60 \%$, or an Adult Comorbidity Evaluation-27 (ACE-27) score of moderate or severe (2 or 3). Non-African American minority patients, those missing race information, and duplicate records were excluded from the final analytic data set.

\section{Statistical analysis}

The Kaplan-Meier method was used to estimate time-to-event curves. The models did not converge when we attempted to control for geographic clustering. We present the racial distribution of key variables (stage at diagnosis, performance stage, and age). To compare differences in unadjusted survival curves between African American and Caucasian patients, we used the log-rank and Wilcoxon tests. Multivariate Cox proportional hazard models were used to examine the association between race and time to event after controlling for the previously mentioned covariates. The Efron method was used to handle ties. ${ }^{23,24}$ Statistical significance was assessed at a conventional alpha level of $\leq 0.05$. Data management and analyses were conducted in Stata 11 (StataCorp LP, College Station, TX, USA) and SAS version 9.2 (SAS Institute Inc, Cary, NC, USA).

\section{Results}

Our final analytic sample consisted of 2,200 patients with NSCLC (Figure 1). At the time of diagnosis, $83 \%$ were Caucasian, $46 \%$ were married, $33 \%$ were aged $55-64$ years, and $47 \%$ lived in the South (Table 1). The majority of patients $(89 \%)$ were diagnosed with metastatic disease, and $65 \%$ had documentation of poor performance status. Overall, the mean time from diagnosis to initiation of treatment (defined as first date of chemotherapy, radiation therapy, or admission to palliative care or hospice; patients may have had multiple treatment modalities) was 66 days, or approximately 2 months. When we examined racial groups separately, the mean times to initiation of treatment were similar for Caucasian and African American patients (65 days versus 72 days, respectively). The mean time between diagnosis and referral to palliative care or hospice was 118 days, with Caucasian

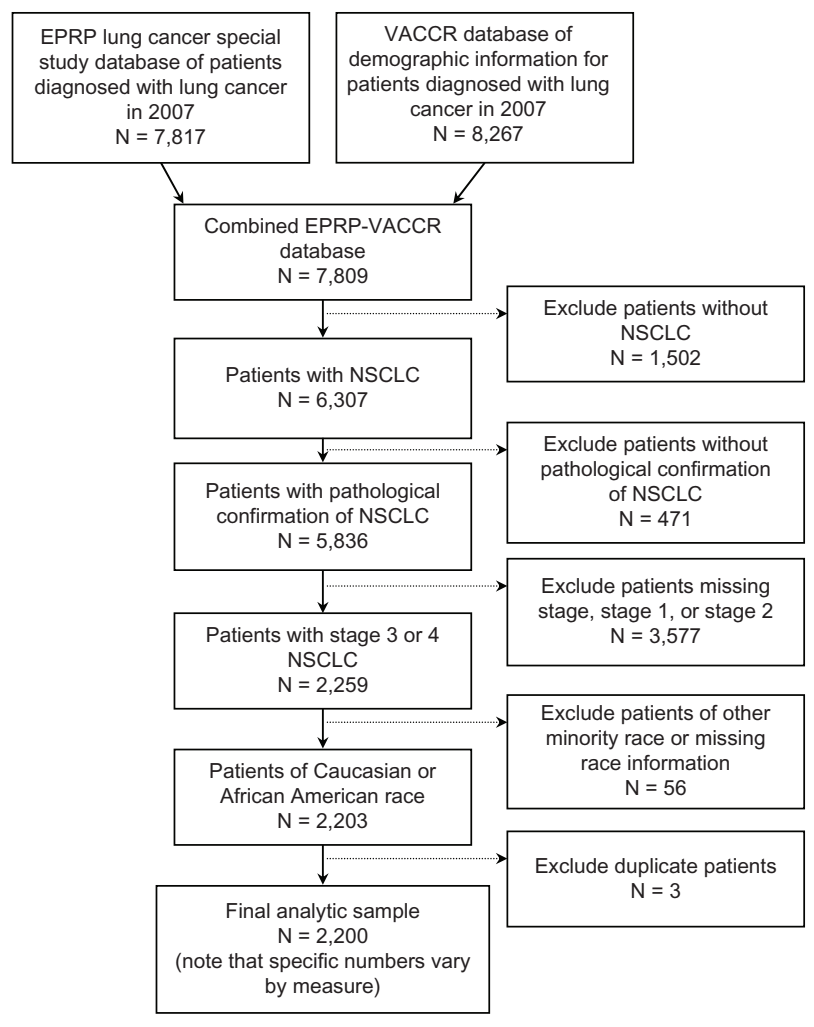

Figure I Lung cancer cohort assembly.

Abbreviations: EPRP, External Peer Review Program; N, number; VACCR, Veterans Affairs Central Cancer Registry; NSCLC, non-small cell lung cancer.

patients being referred an average of 13 days earlier (116 days versus 129 days). The mean time from diagnosis to death was approximately 120 days, or 4 months, with Caucasian patients dying 16 days sooner than African American patients (117 days versus 133 days; Table 1). Patients were similar by race with regard to stage at diagnosis $(P=0.48)$ and performance status $(P=0.85)$.

Approximately $70 \%$ of patients received treatment for their NSCLC. Among patients who received treatment, the mean time to initiation of treatment was 66 days. In unadjusted analysis, there were no racial differences in time to initiation of treatment (Wilcoxon $P=0.94$; log-rank $P=0.99$ ). After adjustment, there remained no association between time to initiation of treatment and race (hazard ratio [HR] 1.04, $P=0.80$ ), marital status (HR 1.00, $P=0.98$ ), age at diagnosis, region, stage at diagnosis (HR $0.87, P=0.47$ ), or performance status (HR 0.81, $P=0.09$; Table 2).

More than half $(54 \%, N=1,178)$ of all patients were referred to palliative care or hospice, with referral occurring approximately 118 days after diagnosis. In unadjusted analyses, there were no racial differences in time to palliative care or hospice referral (Wilcoxon $P=0.29$; log-rank $P=0.57$ ). The lack of association by race remained in the adjusted 
Table I Description of NSCLC patient cohort and key variables

\begin{tabular}{|c|c|c|c|}
\hline & $\begin{array}{l}\text { Caucasian patients } \\
(\mathrm{N}=\mathrm{I}, 826) \\
\%(\mathrm{~N}) \text { or mean (SD) }\end{array}$ & $\begin{array}{l}\text { African American } \\
\text { patients }(\mathrm{N}=374) \text {, } \\
\%(\mathrm{~N}) \text { or mean }(\mathrm{SD})\end{array}$ & $\begin{array}{l}\text { Full sample } \\
(\mathrm{N}=2,200) \\
\%(\mathrm{~N}) \text { or mean }(\mathrm{SD})\end{array}$ \\
\hline \multicolumn{4}{|l|}{ Dependent variables } \\
\hline Days from diagnosis to initiation of treatment $\mathrm{t}^{\mathrm{a}}$ & $64.9(84.2)$ & $71.5(89.8)$ & $66.0(85.2)$ \\
\hline & \multicolumn{2}{|c|}{ care or hospice } & II $7.8(103.6)$ \\
\hline Days from diagnosis to death & $116.8(92.0)$ & $132.9(100.5)$ & II $9.5(93.7)$ \\
\hline \multicolumn{4}{|l|}{ Independent variable } \\
\hline Caucasian race & $100.0 \%(1826)$ & $0.0 \%(374)$ & $83.0 \%(1826)$ \\
\hline \multicolumn{4}{|l|}{ Other control variables } \\
\hline \multicolumn{4}{|l|}{ Age at diagnosis } \\
\hline$<55$ years & $7.0 \%(127)$ & $12.3 \%(46)$ & $7.9 \%(173)$ \\
\hline $55-64$ years & $32.7 \%(597)$ & $36.9 \%(138)$ & $33.4 \%(735)$ \\
\hline $65-74$ years & $26.0 \%(475)$ & $23.8 \%(89)$ & $25.6 \%(564)$ \\
\hline$\geq 75$ years & $27.2 \%(496)$ & $21.4 \%(80)$ & $26.2 \%(576)$ \\
\hline Married & $47.5 \%(866)$ & $35.4 \%(132)$ & $45.5 \%(998)$ \\
\hline \multicolumn{4}{|l|}{ Region } \\
\hline South & $43.8 \%(799)$ & $62.0 \%(232)$ & $46.9 \%(1031)$ \\
\hline North & $13.3 \%(243)$ & $10.2 \%(38)$ & $12.8 \%(28 \mid)$ \\
\hline Central & $23.4 \%(428)$ & $16.0 \%(60)$ & $22.2 \%(488)$ \\
\hline West & $19.5 \%(356)$ & II.8\% (44) & $18.2 \%(400)$ \\
\hline \multicolumn{4}{|l|}{ Stage at diagnosis } \\
\hline Stage 3 & II.3\% (206) & $12.6 \%(47)$ & II.5\% (253) \\
\hline Stage 4 & $88.7 \%(1620)$ & $87.4 \%(327)$ & $88.5 \%(1947)$ \\
\hline Poor performance status ${ }^{b}$ & $65.0 \%(1186)$ & $64.4 \%(24 I)$ & $64.9 \%(1427)$ \\
\hline
\end{tabular}

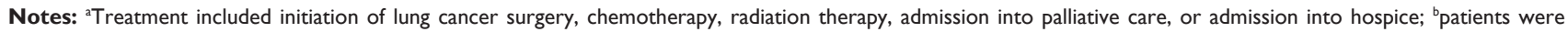
considered to have poor performance if the medical record contained documentation of an Eastern Cooperative Oncology Group score $>2$, a Karnofsky Performance Status Scale score of $<60 \%$, or an Adult Comorbidity Evaluation-27 score of 2 (moderate) or 3 (severe).

Abbreviations: NSCLC, non-small cell lung cancer; N, number; SD, standard deviation.

Cox models (HR 1.10, $P=0.34$; Table 2). Compared with patients with stage 4 disease, those with stage 3 had approximately a $36 \%$ higher hazard of referral (HR $1.37, P<0.01$ ) to palliative care or hospice. Compared with patients with documentation of poor performance status, healthier patients had approximately a $20 \%$ reduced hazard of referral (HR $0.81, P=0.01)$ to palliative care or hospice. There were no other associations between referral and patients' sociodemographic characteristics.

At the time of data collection, approximately $78 \%$ individuals of the sample population were deceased, with a mean time from diagnosis to death of approximately 120 days, or 4 months. In unadjusted analysis, Caucasians died sooner than African Americans (Wilcoxon $P=0.00$; log-rank $P<0.01$ ). This finding remained after adjustment for covariates (HR 0.31, $P<0.01$ ). Being married (HR 0.89, $P=0.02$ ) and being less than 55 years of age (HR $0.76, P=0.01$ ) were protective against death compared with being unmarried or $>75$ years old at diagnosis. Geographic region was not associated with time to death. Compared with those with metastatic disease, patients with stage 3 disease had approximately a $50 \%$ reduced hazard of death (HR $0.53, P<0.01$ ).
Poor performance status was also associated with time to death (HR 0.80, $P<0.01$; Table 2).

\section{Discussion}

We examined two dimensions of quality of VA NSCLC care: processes of care (time to treatment) and outcomes (survival). Among patients with late-stage NSCLC, we observed no racial differences in processes of care. In fact, there were no significant associations between time from diagnosis to initiation of treatment and any patient-level characteristics. This supports the VA's reputation as an equal-access system. The mean time to first treatment that we observed, approximately 66 days, is consistent with a previous VA study of advanced NSCLC. ${ }^{25}$ Although some have argued that a 2-month delay may negatively affect patients' emotional states, ${ }^{26}$ there are no formalized guidelines regarding timeliness of treatment for NSCLC. Thus, these findings suggest that the VA provides equitable and timely access to critical health services for patients with late-stage NSCLC.

Palliative care is critical for effective management of pain and other distressing symptoms and is often provided in conjunction with other therapies. Recent literature has 
Table 2 Cox proportional hazard model regression results

\begin{tabular}{|c|c|c|c|c|c|c|c|c|c|}
\hline & \multicolumn{3}{|c|}{$\begin{array}{l}\text { Diagnosis to } \\
\text { treatment initiation }^{a}\end{array}$} & \multicolumn{3}{|c|}{$\begin{array}{l}\text { Diagnosis to referral to } \\
\text { palliative care or hospice }\end{array}$} & \multicolumn{3}{|c|}{ Diagnosis to death } \\
\hline & HR & $95 \% \mathrm{Cl}$ & $P$-value & HR & $95 \% \mathrm{Cl}$ & $P$-value & HR & $95 \% \mathrm{Cl}$ & $P$-value \\
\hline \multicolumn{10}{|c|}{ Demographic characteristics } \\
\hline Caucasian race & 1.04 & $0.78-1.37$ & 0.80 & 1.10 & $0.91-1.34$ & 0.34 & 0.31 & $1.14-1.50$ & $<0.01 *$ \\
\hline Married & 1.00 & $0.8 I-1.25$ & 0.98 & 1.02 & $0.88-1.12$ & 0.78 & 0.89 & $0.81-0.99$ & $0.02 *$ \\
\hline \multicolumn{10}{|l|}{ Age at diagnosis } \\
\hline$<55$ years & 0.82 & $0.56-1.22$ & 0.34 & 0.83 & $0.63-1.10$ & 0.19 & 0.76 & $0.62-0.92$ & $0.01 *$ \\
\hline $55-64$ years & 0.97 & $0.75-1.27$ & 0.83 & 0.90 & $0.75-1.09$ & 0.27 & 0.89 & $0.80-1.00$ & 0.06 \\
\hline $65-74$ years & 1.04 & $0.79-1.37$ & 0.79 & 0.99 & $0.82-1.20$ & 0.92 & 0.88 & $0.78-1.00$ & 0.06 \\
\hline $\begin{array}{l}\geq 75 \text { years } \\
\text { (reference) }\end{array}$ & & & & & & & & & \\
\hline \multicolumn{10}{|l|}{ Region } \\
\hline North & 1.02 & $0.7 I-1.46$ & 0.92 & 0.87 & $0.67-1.13$ & 0.29 & 1.10 & $0.95-1.28$ & 0.19 \\
\hline Central & 0.89 & $0.67-1.18$ & 0.40 & 0.89 & $0.73-1.08$ & 0.24 & 1.13 & $1.00-1.27$ & 0.06 \\
\hline West & 0.87 & $0.64-1.17$ & 0.36 & 0.96 & $0.78-1.18$ & 0.69 & 1.08 & $0.95-1.24$ & 0.23 \\
\hline South (ref) & & & & & & & & & \\
\hline $\begin{array}{l}\text { Poor performance } \\
\text { status }\end{array}$ & 0.81 & $0.64-1.03$ & 0.09 & 0.81 & $0.69-0.95$ & $0.01 *$ & 0.80 & $0.72-0.89$ & $<0.01 *$ \\
\hline \multicolumn{10}{|l|}{ Stage at diagnosis } \\
\hline Stage 3 & 0.87 & $0.59-1.28$ & 0.47 & 1.37 & $1.13-1.64$ & $<0.0 I^{*}$ & 0.53 & $0.45-0.63$ & $<0.01 *$ \\
\hline Stage 4 (ref) & & & & & & & & & \\
\hline $\mathrm{N}$ & 2,098 & & & 2,149 & & & 2,190 & & \\
\hline
\end{tabular}

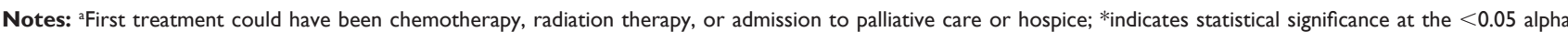
level.

Abbreviations: $\mathrm{HR}$, hazard ratio; $\mathrm{Cl}$, confidence interval; $\mathrm{N}$, number.

suggested that enrollment in hospice does not compromise the length of survival for patients after advanced lung cancer diagnosis, ${ }^{27}$ and may in fact extend life by 2 months. ${ }^{28}$ As a result, some have suggested that patients be referred to palliative care within 4 to 6 weeks of diagnosis. ${ }^{29} \mathrm{In}$ the absence of timeliness standards, it is clear that the VA is committed to referring all patients in a common timeframe. We found that more than half of patients with advanced NSCLC were referred to palliative care or hospice services, with no significant racial differences. Moreover, these data suggest that patients seem to be referred appropriately on the basis of their health status, because patients with metastatic disease or poor performance status were sent to palliative care and/or hospice more quickly.

We also examined survival rates up to 2 years from diagnosis. As anticipated, we found that metastatic disease, poor performance status, and increased age at diagnosis were associated with shorter survival times. Marriage had a protective effect, which has also been demonstrated in prior studies..$^{30}$ In these data, African American patients survived a mean of 16 days longer than Caucasian patients, even after we controlled for prespecified covariates. Although racial differences in survival time have been documented in nonfederal health care systems, our finding is consistent with several studies that suggested that once equal access to care has been obtained, survival rates are similar for patients of diverse races. ${ }^{22,31,32}$

Our study has several limitations. First, our analysis was limited to care received in the VA. Some patients receiving care in the VA health care system may also receive a portion of their cancer care in the private sector. Analysis was also limited to patients of African American and Caucasian race without regard to Hispanic ethnicity. Geographic regions were defined based on landmass, not distribution of this sample of VA patients. Future research should endeavor to include information from multiple data sources on a more diverse patient cohort. We obtained death information 2 years after diagnosis; however, this seems reasonable, because $78 \%$ of our sample died within this timeframe. We also looked for racial differences in right-censoring of the data. At the time of data capture, approximately $81 \%$ of African Americans and $88 \%$ of Caucasian patients were deceased $(P<0.01)$. Future studies should endeavor to include longer-term follow-up data to avoid potential censoring bias.

Our findings provided important insights on the quality and timeliness of VA NSCLC care. We assessed key process and outcome measures of care quality and observed no evidence of clinically meaningful racial differences in timeliness of NSCLC care provided by the VA health care system. To validate these findings, future studies that follow 
patients longitudinally should be conducted. These results may reflect the VA's history as an equal-access system, ${ }^{18,33,34}$ and its established commitment to ongoing quality monitoring and improvement.

\section{Acknowledgments}

This study was supported by the Durham VA Center for Health Services Research in Primary Care (HSR\&D) Center of Excellence. Development of the data set was funded by funds transferred from the Veterans Health Administration Office of Quality and Performance to the HSR\&D Center of Excellence at the Durham VA Medical Center. Dr Zullig was funded by the National Cancer Institute (5R25CA116339). Dr Weinberger is a VA HSR\&D Senior Research Career Scientist (RCS 91-408). The authors report no other conflicts of interest in this work.

\section{Disclosure}

The authors report no conflicts of interest in this work.

\section{References}

1. Siegel R, Naishadham D, Jemal A. Cancer statistics, 2012. CA Cancer J Clin. 2012;62(1):10-29.

2. American Cancer Society [homepage on the Internet]. Non-small cell lung cancer. Atlanta, GA: American Cancer Society; 2013. Available from: http://www.cancer.org/cancer/lungcancer-non-smallcell/. Accessed July 11, 2013.

3. Cooper GS, Virnig B, Klabunde CN, Schussler N, Freeman J, Warren JL. Use of SEER-Medicare data for measuring cancer surgery. Med Care. 2002;40(Suppl 8):IV-43-48.

4. Pfister DG, Johnson DH, Azzoli CG, et al; for American Society of Clinical Oncology. American Society of Clinical Oncology treatment of unresectable non-small-cell lung cancer guideline: update 2003. J Clin Oncol. 2004;22(2):330-353.

5. Hardy D, Xia R, Liu CC, Cormier JN, Nurgalieva Z, Du XL. Racial disparities and survival for nonsmall-cell lung cancer in a large cohort of black and white elderly patients. Cancer. 2009;115(30):4807-4818.

6. Committee on Quality of Health Care in America, Institute of Medicine. Crossing the Quality Chasm: A New Health System for the 21st Century. Washington, DC: The National Academies Press; 2001.

7. Olsson JK, Schultz EM, Gould MK. Timeliness of care in patients with lung cancer: a systematic review. Thorax. 2009;64(9):749-756.

8. Gould MK, Schultz EM, Wagner TH, et al. Disparities in lung cancer staging with positron emission tomography in the Cancer Care Outcomes Research and Surveillance (CanCORS) study. J Thorac Oncol. 2011;6(5):875-883.

9. Margolis ML, Christie JD, Silvestri GA, Kaiser L, Santiago S, HansenFlaschen J. Racial differences pertaining to a belief about lung cancer surgery: results of a multicenter survey. Ann Intern Med. 2003;139(7): 558-563.

10. Farjah F, Wood DE, Yanez ND 3rd, et al. Racial disparities among patients with lung cancer who were recommended operative therapy. Arch Surg. 2009;144(1):14-18.

11. Landrum MB, Keating NL, Lamont EB, Bozeman SR, McNeil BJ. Reasons for underuse of recommended therapies for colorectal and lung cancer in the Veterans Health Administration. Cancer. 2012;118(13): 3345-3355.
12. Shugarman LR, Mack K, Sorbero ME, et al. Race and sex differences in the receipt of timely and appropriate lung cancer treatment. Med Care. 2009;47(7):774-781.

13. Landrum MB, Keating NL, Lamont EB, et al. Survival of older patients with cancer in the Veterans Health Administration versus fee-for-service Medicare. J Clin Oncol. 2012;30(10):1072-1079.

14. Morris AM, Rhoads KF, Stain SC, Birkmeyer JD. Understanding racial disparities in cancer treatment and outcomes. J Am Coll Surg. 2010; 211(1):105-113.

15. Bach PB, Cramer LD, Warren JL, Begg CB. Racial differences in the treatment of early-stage lung cancer. N Engl J Med. 1999;341(16): 1198-1205.

16. Jahanzeb M, Virgo K, McKirgan L, Johnson F. Evaluation of outcome by race in early-stage non-small cell lung cancer. Oncol Rep. 1997;4(1): 183-186.

17. Williams CD, Provenzale D, Stechuchak KM, Kelley MJ. Impact of race on early-stage lung cancer treatment and outcome. Fed Pract. 2012.

18. Kizer KW, Dudley RA. Extreme makeover: transformation of the veterans health care system. Annu Rev Public Health. 2009;30:313-339.

19. Williams CD, Stechuchak KM, Zullig LL, Provenzale D, Kelley MJ. Influence of comorbidity on racial differences in receipt of surgery among US veterans with early-stage non-small-cell lung cancer. J Clin Oncol. 2013;31(4):475-481.

20. Zullig LL, Jackson GL, Dorn RA, et al. Cancer incidence among patients of the US Veterans Affairs Health Care System. Mil Med. 2012;177(6):693-701.

21. Pagano E, Filippini C, Di Cuonzo D, et al. Factors affecting pattern of care and survival in a population-based cohort of non-small-cell lung cancer incident cases. Cancer Epidemiol. 2010;34(4):483-489.

22. Zheng L, Enewold L, Zahm SH, et al. Lung cancer survival among black and white patients in an equal access health system. Cancer Epidemiol Biomarkers Prev. 2012;21(10):1841-1847.

23. Cleves M, Gould W, Gutierrez RG, Marchenko YV. An Introduction to Survival Analysis Using Stata. 3rd ed. College Station, TX: Stata Press; 2010 .

24. Kleinbaum DG. Survival Analysis: A Self-Learning Text. New York, NY: Springer-Verlag Inc; 1996.

25. Schultz EM, Powell AA, McMillan A, et al. Hospital characteristics associated with timeliness of care in veterans with lung cancer. Am J Respir Crit Care Med. 2009;179(7):595-600.

26. Gould MK. Delays in lung cancer care: time to improve. JThorac Oncol. 2009;4(11):1303-1304.

27. Saito AM, Landrum MB, Neville BA, Avanian JZ, Weeks JC, Earle CC. Hospice care and survival among elderly patients with lung cancer. J Palliat Med. 2011;14(8):929-939.

28. Temel JS, Greer JA, Muzikansky A, et al. Early palliative care for patients with metastatic non-small-cell lung cancer. $N$ Engl J Med. 2010;363(8):733-742.

29. von Gunten CF, Lutz S, Ferris FD. Why oncologists should refer patients earlier for hospice care. Oncology (Williston Park). 2011;25(13): 1278-1280, 1282-1285.

30. Siddiqui F, Bae K, Langer CJ, et al. The influence of gender, race, and marital status on survival in lung cancer patients: analysis of Radiation Therapy Oncology Group trials. J Thorac Oncol. 2010;5(5):631-639.

31. Bradley CJ, Given CW, Roberts C. Disparities in cancer diagnosis and survival. Cancer. 2001;91(1):178-188.

32. Akerley WL 3rd, Moritz TE, Ryan LS, Henderson WG, Zacharski LR. Racial comparison of outcomes of male Department of Veterans Affairs patients with lung and colon cancer. Arch Intern Med. 1993;153(14): 1681-1688.

33. Robinson CN, Balentine CJ, Marshall CL, et al. Ethnic disparities are reduced in VA colon cancer patients. Am J Surg. 2010;200(5): 636-639.

34. Perlin JB, Kolodner RM, Roswell RH. The Veterans Health Administration: quality, value, accountability, and information as transforming strategies for patient-centered care. Am J Manag Care. 2004;10(11 Pt 2):828-836. 


\section{Publish your work in this journal}

Cancer Management and Research is an international, peer-reviewed open access journal focusing on cancer research and the optimal use of preventative and integrated treatment interventions to achieve improved outcomes, enhanced survival and quality of life for the cancer patient The journal welcomes original research, clinical \& epidemiological studies, reviews \& evaluations, guidelines, expert opinion \& commentary, case reports \& extended reports. The manuscript management system is completely online and includes a very quick and fair peerreview system, which is all easy to use. Visit http://www.dovepress.com/ testimonials.php to read real quotes from published authors.

Submit your manuscript here: http://www.dovepress.com/cancer-management-and-research-journal 